\title{
Quality of clinicians' conversations with patients and families before and after implementation of the Serious Illness Care Program in a hospital setting: a retrospective chart review study
}

\author{
Christina Ma MD, Lauren E. Riehm MD, Rachelle Bernacki MD MS, Joanna Paladino MD, \\ John J. You MD MSc
}

\section{Abstract}

Background: Seriously ill patients in hospital have indicated that better communication with practitioners is vital for improving care. The aim of this study was to assess whether the quality of conversations about serious illness improved after implementation of the Serious IIIness Care Program (SICP).

Methods: In this retrospective chart review study, we evaluated patients who were admitted to a medical ward at Hamilton General Hospital, had a stay of at least 48 hours, and were at risk for a lengthy stay or increased need for community-based services (interRAI Emergency Department Screener score of 5 or 6). The SICP study period was from Mar. 1, 2017, to Jan. 19, 2018. We used a validated codebook to assess the quality of documented conversations regarding serious illness for eligible patients before (usual care [control group]) and after SICP implementation (intervention group), specifically examining the following domains: patients' values and goals, understanding of prognosis and illness, end-of-life care planning, and code status or desire for other life-sustaining treatments.

Results: The study sample included 56 patients in the control group and 56 patients in the intervention group. The overall quality of documented conversations about serious illness was significantly higher in the intervention group than in the control group ( $p<$ $0.001)$ and was significantly higher in the subdomains of values and goals $(p<0.001)$, understanding of prognosis and illness $(p<$ $0.001)$ and life-sustaining treatments $(p=0.03)$ but not end-of-life care planning $(p=0.48)$.

Interpretation: Implementation of the SICP in a hospital setting was associated with higher quality of documented conversations regarding serious illness with patients at high risk for clinical or functional deterioration. The SICP is transferable and adaptable to a hospital setting, and was associated with an increase in adherence to best practices compared to usual care.

urrent communication practices often do not meet the needs of seriously ill patients in hospital. For example, there is a lack of honest discussion surrounding prognosis and insufficient exploration of patients' values. ${ }^{1-3}$ According to inpatients and their families, however, discussion of these issues is important to support highquality care. ${ }^{2}$ As a result of these gaps in communication, patients may receive invasive treatments that are discordant with their values and goals. ${ }^{3-5}$ Inadequate communication during serious illness also has a negative impact on patients' satisfaction with care and can create distress for surrogate decision-makers. ${ }^{6}$ Evidence suggests that improved communication earlier in the illness trajectory about the patient's values, goals and priorities can substantially ameliorate some of this emotional burden. ${ }^{6}$

The Serious Illness Care Program (SICP) is a multicomponent communication intervention that aims to build capacity to have more frequent, earlier and more person-centred conversations about serious illness with patients facing life-limiting illness. ${ }^{7-9}$ The rationale for this program is that scalable solutions are needed to equip non-palliative-care clinicians with communication skills that can enable them to initiate a palliative approach to care earlier in the illness trajectory without needing to involve palliative care practitioners.

Although the SICP was originally designed for outpatient oncology practice and has been implemented successfully in

\section{Competing interests: None declared.}

This article has been peer reviewed.

Correspondence to: John You, John.You@thp.ca

CMAJ Open 2020. DOI:10.9778/cmajo.20190193 
primary care,${ }^{10}$ we judged that it addressed many of the communication gaps in the hospital setting. ${ }^{3,4}$ Therefore, we adapted the SICP for an inpatient setting and implemented it on the medical wards of our hospital. Specifically, we sought to determine whether the quality of conversations was higher during the SICP implementation period compared to historical controls among medical patients in hospital at increased risk for a lengthy hospital stay or need for community-based services with whom clinicians had had a conversation about serious illness. We hypothesized that the quality of conversations would be higher in the intervention group than in the control group.

\section{Methods}

\section{Design and setting}

We conducted a retrospective chart review to assess the quality of conversations regarding serious illness during implementation of the SICP compared to historical controls (i.e., usual care). In this article, we define a conversation regarding serious illness as any conversation between a practitioner and a patient with serious life-limiting illness or the surrogate decision-maker(s) about understanding of the illness and prognosis, values, fears and sources of strength, with the intent to inform current or future decisions about treatment. ${ }^{9}$ The SICP was implemented on the general internal medicine wards at Hamilton General Hospital, in Hamilton, Ontario. The average number of patients admitted monthly to the Internal Medicine program at the hospital in 2017 was 388. The SICP study period was from Mar. 1, 2017, to Jan. 19, 2018.

The Hamilton General Hospital was the vanguard site in ongoing multisite implementation of the SICP at 3 other Canadian hospitals. This paper reports the results of a focused assessment of the quality of conversations about serious illness before and after SICP implementation at this site.

\section{Intervention and its adaptation to hospital setting}

The SICP was originally designed for the outpatient oncology setting. It includes tools for clinicians and family, an educational component and a system change component. Tools include a previsit letter for patients (which introduces the topics to consider before the conversation with their clinician), the Serious Illness Conversation Guide (Appendix 1, available at www.cmajopen.ca/content/8/2/E448/suppl/DC1), the Clinician Reference Guide (which summarizes information provided in the training and offers guidance on challenging scenarios) and a Family Communication Guide for patients and their families (which suggests an approach for discussing their illness and care preferences with their family).

The primary educational component consists of a 2.5-hour interactive clinician training workshop. System change refers to the design and implementation of the following processes to enable conversations about serious illness in practice: identifying suitable patients, prompting clinicians to have the conversation with eligible patients, having the conversation using the guide and documenting the conversation in the medical record.
Clinicians were eligible for training if they were full-time attending physicians or nurse practitioners on participating medical wards. Although the tools and clinician training components of the SICP did not require modification (other than adjusting the previsit letter to reflect the hospital setting rather than a clinic visit), we made adjustments to the original program to tailor processes for a hospital setting more generally and for our local context more specifically (Table 1).

\section{Control group}

Before the SICP study period, we had conducted 2 planned cross-sectional sampling exercises that collected data on basic demographic characteristics (age, sex, comorbidities [using the Charlson Comorbidity Index $\left.{ }^{11}\right]$ ) and score on the interRAI Emergency Department Screener ${ }^{12}$ at the time of admission for all medical inpatients at Hamilton General Hospital, on a single arbitrarily chosen day in December 2016 and on a single arbitrarily chosen day in February 2017. The interRAI Emergency Department Screener is a brief, validated, proprietary instrument. ${ }^{12}$ Possible scores range from 1 to 6 , with higher scores predicting an increased risk of a lengthy hospital stay or need for community-based services.

To enable comparison of the quality of conversations about serious illness during implementation of the SICP and with usual care, we identified a control group (i.e., unexposed to the SICP) consisting of any patients from these 2 crosssectional samples who had a length of stay of at least 48 hours and had a score of 5 or 6 on the interRAI Emergency Department Screener. This process yielded a sample of 56 control patients.

\section{Intervention group}

Patients were eligible to be enrolled in the SICP if they were admitted to a medical ward at Hamilton General Hospital, had a stay of at least 48 hours, and received a score of 5 or 6 on the interRAI Emergency Department Screener, administered by a trained nurse at the time of hospital admission. A unit champion was hired to support our quality-improvement initiative. The roles of the unit champion were to trigger clinicians to have a conversation about serious illness with eligible patients, prepare the patient and family for the conversation by reviewing the content in the previsit letter, and schedule a formal meeting.

The attending medical team delivered the intervention to a convenience sample of patients. We used a convenience sample for the following reasons: the intervention could not be delivered to all eligible patients because of limitations on the maximum number of conversations a clinician could feasibly hold during a typical workweek (e.g., 1-2 per week, in our experience); some patients were discharged from hospital, transferred to another service or facility, or died before a conversation could be arranged; and some eligible patients declined to participate in the program. For this retrospective chart review study, we abstracted data for consecutive patients with whom the conversation about serious illness was held during the study period to reach a target ratio of intervention to control patients of 1:1. 
Table 1: Adaptation of the Serious IlIness Care Program to the hospital medical ward setting

\begin{tabular}{|c|c|c|}
\hline Component & Original in oncology clinic & Adaptation to hospital medical ward \\
\hline Tools & Previsit letter & $\begin{array}{l}\text { Script adjusted to reflect hospital setting rather than } \\
\text { clinic visit }\end{array}$ \\
\hline & Serious Illness Conversation Guide & No changes \\
\hline & Clinician Reference Guide & No changes \\
\hline & Family communication guide & No changes \\
\hline Clinician training & $\begin{array}{l}\text { 2.5-h workshop including reflection; didactic } \\
\text { teaching skills practice involving role play using the } \\
\text { Serious Illness Conversation Guide with } \\
\text { standardized patients; and direct observation and } \\
\text { feedback from expert faculty }\end{array}$ & No changes \\
\hline \multicolumn{3}{|l|}{ System change } \\
\hline Patient identification & $\begin{array}{l}\text { "No" response to question "Would you be surprised } \\
\text { if this patient died in the next year?" }\end{array}$ & $\begin{array}{l}\text { Leveraged an existing hospital initiative to screen all } \\
\text { patients in the emergency department aged } \geq 65 \mathrm{yr} \\
\text { at the time of admission with the interRAl } \\
\text { Emergency Department Screener; patients with a } \\
\text { score of } 5 \text { or } 6 \text { who had a stay of at least } 48 \mathrm{~h} \text { on the } \\
\text { medical ward were eligible }\end{array}$ \\
\hline Reminding clinicians & $\begin{array}{l}\text { Email sent the day before the clinic visit notifying } \\
\text { the clinician that the patient is due for a } \\
\text { conversation about serious illness; on the day of the } \\
\text { visit, the Serious Illness Conversation Guide is } \\
\text { placed with the face sheet that is given to clinicians } \\
\text { before each patient visit }\end{array}$ & $\begin{array}{l}\text { Hired a unit champion (former bedside nurse from } \\
\text { the medical ward), who reminded clinicians in } \\
\text { person, by telephone or by text message to have a } \\
\text { conversation about serious illness with eligible } \\
\text { inpatients under their care }\end{array}$ \\
\hline Patient preparation & Previsit letter mailed to eligible patients & $\begin{array}{l}\text { Unit champion prepared patients/families in hospital } \\
\text { using the script adapted from the previsit letter }\end{array}$ \\
\hline $\begin{array}{l}\text { Conversation using Serious } \\
\text { Illness Conversation Guide }\end{array}$ & During outpatient visit in clinic room & $\begin{array}{l}\text { During hospital stay, in a private meeting room on } \\
\text { the ward }\end{array}$ \\
\hline $\begin{array}{l}\text { Documentation of } \\
\text { conversation }\end{array}$ & $\begin{array}{l}\text { Electronic medical record module using a } \\
\text { structured format that aligns with the items in the } \\
\text { Serious IIIness Conversation Guide }\end{array}$ & $\begin{array}{l}\text { Dictated, structured clinical note that aligned with the } \\
\text { items in the Serious Illness Conversation Guide; the } \\
\text { transcribed note was placed in the patient's } \\
\text { electronic medical record and automatically faxed to } \\
\text { the patient's primary care physician (e.g., using the } \\
\text { same workflow as for consultation notes and } \\
\text { discharge summaries) }\end{array}$ \\
\hline Patient and family support & $\begin{array}{l}\text { After the conversation, the clinician gives the } \\
\text { patient the Family Communication Guide }\end{array}$ & $\begin{array}{l}\text { After the conversation (typically } 24-48 \mathrm{~h} \text { ), the unit } \\
\text { champion gave patients/families the Family } \\
\text { Communication Guide and also provided in-person } \\
\text { support and debriefing }\end{array}$ \\
\hline
\end{tabular}

\section{Data extraction}

We extracted the following information from the medical records of patients in the intervention and control groups: baseline characteristics (demographic characteristics, comorbidities [summarized using the Charlson Comorbidity Index score], use of health care services and laboratory test results on admission), quality of the conversation about serious illness, how the conversation was documented (dictated, transcribed note $\mathrm{v}$. handwritten progress note) and type of clinician who led the conversation.

To train assessors for data extraction, the senior investigator (J.J.Y.) and 2 coinvestigators (C.M., L.R.) participated in a calibration exercise to enhance interrater reliability of chart abstraction. The 3 investigators abstracted data from the medical records of both patient groups independently using a structured, validated codebook that was developed to rate the quality of conversations about serious illness ${ }^{10}$ (Appendix 2, available at www.cmajopen.ca/content/8/2/E448/suppl/DC1). The codebook uses 4 domains to evaluate the quality of the conversations: patient values and goals (scored on a scale of $0-7$ ), understanding of prognosis and illness (scored on a scale of 0-4), planning for end-of-life care (scored on a scale of $0-4)$, and code status or desire for other life-sustaining treatments (scored on a scale of 0-2). The maximum score is 17 , with higher scores indicating higher-quality conversations. The investigators abstracted data independently from the same 6 randomly selected charts (3 from the intervention group and 3 from the control group) and compared their results to reach consensus and ensure consistency.

The trained assessors (C.M., L.R.) used a structured data collection form and the codebook to independently evaluate one-half each of the control and intervention group charts. 


\begin{tabular}{|c|c|c|c|}
\hline \multirow[b]{2}{*}{ Variable } & \multicolumn{2}{|c|}{ Group; mean $\pm \mathrm{SD}^{*}$} & \multirow[b]{2}{*}{$p$ value } \\
\hline & $\begin{array}{l}\text { Intervention } \\
\quad n=56\end{array}$ & $\begin{array}{l}\text { Control } \\
n=56\end{array}$ & \\
\hline $\begin{array}{l}\text { Age at time of conversation about } \\
\text { serious illness, yr }\end{array}$ & $76.2 \pm 11.8$ & $80.1 \pm 11.4$ & 0.08 \\
\hline Male sex, no. (\%) & $26(46)$ & $25(45)$ & 0.8 \\
\hline Charlson Comorbidity Index score & $0.9 \pm 1.5$ & $1.1 \pm 1.3$ & 0.9 \\
\hline $\begin{array}{l}\text { No. of emergency department visits in } \\
\text { previous year }\end{array}$ & $2.7 \pm 2.7$ & $3.6 \pm 4.3$ & 0.2 \\
\hline $\begin{array}{l}\text { Arrived in emergency department by } \\
\text { ambulance, no. (\%) }\end{array}$ & $41(73)$ & $50(89)$ & 0.05 \\
\hline $\begin{array}{l}\text { Seen in cancer clinic in previous } 6 \mathrm{mo} \\
\text { no. }(\%)\end{array}$ & $8(14)$ & $2(4)$ & 0.09 \\
\hline \multicolumn{4}{|l|}{ Laboratory valuest } \\
\hline Hematocrit & $0.34 \pm 0.08$ & $0.35 \pm 0.06$ & 0.4 \\
\hline Creatinine level, $\mu \mathrm{mol} / \mathrm{L}$ & $145 \pm 114$ & $162 \pm 152$ & 0.5 \\
\hline Albumin level, g/L & $28 \pm 5.9$ & $29 \pm 5.7$ & 0.2 \\
\hline Bilirubin level, $\mu \mathrm{mol} / \mathrm{L}$ & $16 \pm 13$ & $18 \pm 20$ & 0.7 \\
\hline $\begin{array}{l}\text { High-sensitivity troponin I level, ng/L, } \\
\text { median (IQR) }\end{array}$ & $20(9-71)$ & $31(12-66)$ & $0.6 \ddagger$ \\
\hline $\begin{array}{l}\text { Note: IQR = interquartile range, } S D=\text { standard de } \\
\text { *Except where noted otherwise. } \\
\text { †The most abnormal result from } 48 \text { hours before } h \\
\text { fMann-Whitney test used since data were not dis }\end{array}$ & admission to 6 & & \\
\hline
\end{tabular}

To maintain consistency, every 10th chart was coded in duplicate by the second assessor, and the assessors' results were compared at regular intervals.

When assessing the quality of documented conversations about serious illness, dictated and written progress notes from patient charts were eligible to be coded. There was a substantial amount of heterogeneity in how conversations were documented in the control charts. To capture all potential conversations in this group, we used a low threshold to include notes as conversations about serious illness: conversations were considered conversations about serious illness if they were scored 1 point or more with the use of the codebook. Furthermore, some control charts had more than 1 documented conversation that were scored at least 1 point. In these cases, we used the conversation with the highest score in the analysis. Control charts without documented conversations regarding serious illness were excluded from the analysis.

The type of clinician who led the conversation was determined and based on who was explicitly stated in the clinical note as having led the conversation or, if this information was not included, the type of clinician who signed the note.

\section{Statistical analysis}

We used descriptive statistics to summarize the distributions of demographic and clinical characteristics of the intervention and control patients and compared the distributions using an unpaired $t$ test for continuous variables and the $\chi^{2}$ test for cat- egoric variables. The significance level was set at $p \leq 0.05$. We used the Mann-Whitney test to compare the difference in codebook scores of the intervention and control groups, and the $\chi^{2}$ test or Fisher exact test to compare individual codebook items (present/not present) between the 2 groups.

\section{Sensitivity analysis}

We also conducted a sensitivity analysis to compare the quality of documented conversations about serious illness in the intervention and control groups, stratified by conversations that were led by attending physicians versus those that were led by other clinicians (residents or nurse practitioners).

\section{Ethics approval}

Ethics approval was obtained for this retrospective chart review study from the Hamilton Integrated Research Ethics Board.

\section{Results}

Of the 26 eligible clinicians (22 attending physicians and 4 nurse practitioners), 21 (81\%) (17 attending physicians and 4 nurse practitioners) took part in the SICP training session.

During the implementation period, the unit champion screened 391 medical inpatients for eligibility and identified 275 eligible patients, of whom 219 were excluded owing to clinician time limits; the patient was discharged from hospital, 
transferred or died; or the patient declined to participate. There were no statistically significant differences in baseline characteristics between the intervention and control groups (Table 2).

Fifty-five patients (98\%) in the intervention group had a conversation about serious illness documented in the medical record, of which 39 (71\%) were documented as dictated, transcribed notes in the electronic medical record, and 16 (29\%) were documented as written progress notes in the paper chart. Of the 56 patients in the control group, 28 (50\%) had a conversation documented in the medical record, of which 5 (18\%) were dictated and transcribed in the electronic medical record, and 23 (82\%) were documented as written progress notes. All the transcribed notes in the intervention group were dedicated notes containing information pertinent to the conversation, whereas all the transcribed notes in the control group contained additional information that was not directly pertinent to the conversation. Conversations about serious illness were more likely to be led by attending physicians (v. residents or nurse practitioners) in the intervention group (48 v. 7) than the control group (12 v. 16) $(p<0.001)$.

\section{Quality of conversations about serious illness}

The overall quality of the conversations about serious illness was significantly higher in the intervention group than in the control group $(p<0.001)$ (Figure 1; Appendix 3, Supplemental
Table S1, available at www.cmajopen.ca/content/8/2/E448/ suppl/DC1). Domain scores were also significantly higher in the intervention group than in the control group except for the end-of-life care planning domain $(p=0.48)$. Furthermore, most individual codebook items were present significantly more often in the intervention group than in the control group (Appendix 3, Supplemental Table S2).

In the sensitivity analysis comparing the quality of documented conversations regarding serious illness in the intervention and control groups, we found that the quality of conversations was higher in the intervention group than in the control group for both conversations that were led by attending physicians and those that were led by other clinicians (residents or nurse practitioners) (Table 3 ).

\section{Interpretation}

In this single-centre retrospective chart review study, we found that the quality of documented conversations regarding serious illness after implementation of the SICP was significantly higher than during usual care. In particular, after SICP implementation, the clinician and patient more often discussed patient values and goals, and understanding of prognosis and illness. We also found that conversations about serious illness were more clearly documented and more retrievable after SICP implementation.

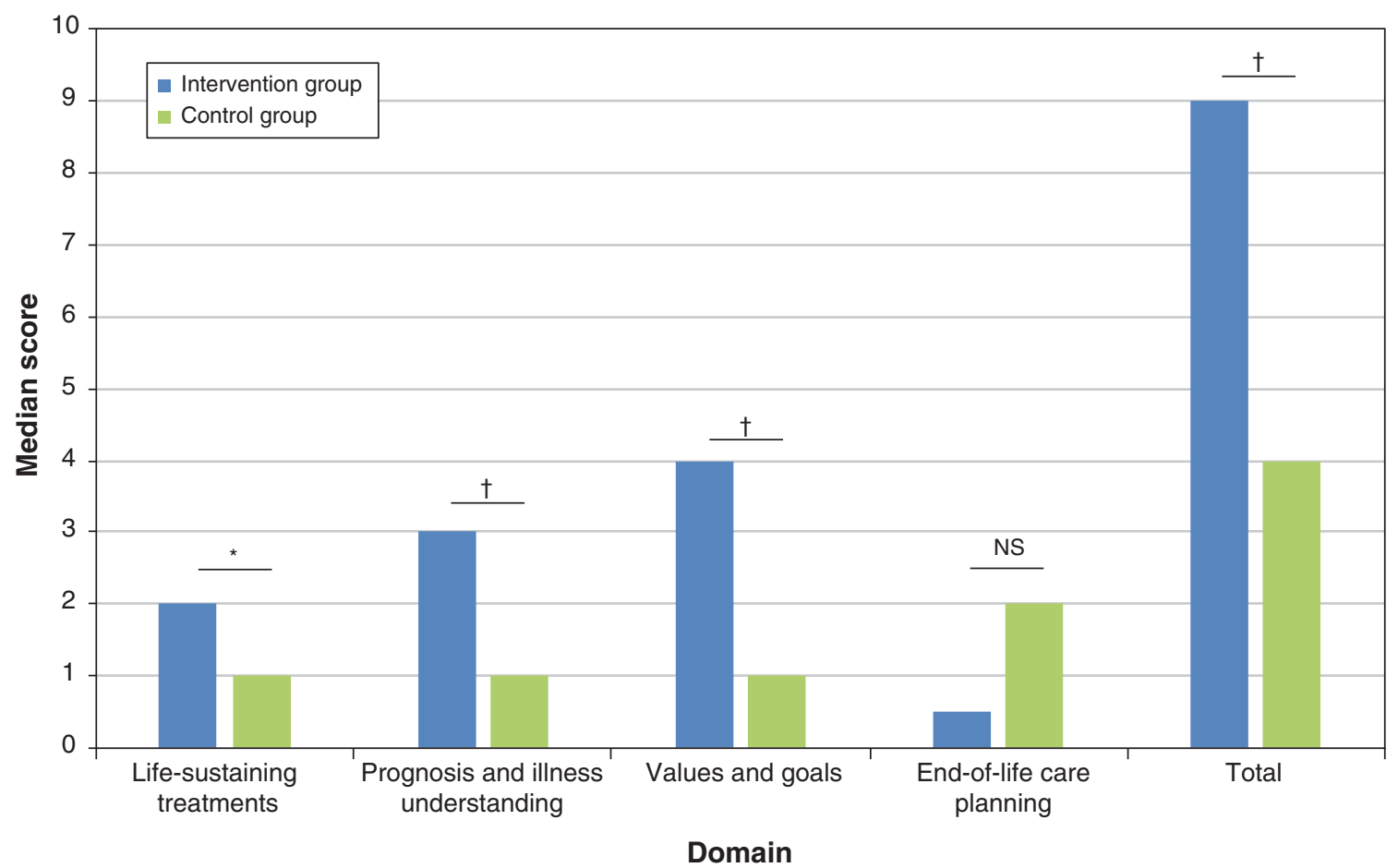

Figure 1: Median scores for quality of conversations about serious illness in the intervention and control groups. Life-sustaining treatments scored on a scale of $0-2$, prognosis and illness understanding scored on a scale of $0-4$, values and goals scored on a scale of $0-7$, and end-oflife care planning scored on a scale of $0-4$ (total 17). Note: NS $=$ not significant. ${ }^{*} p=0.03, \dagger p<0.001$. 
Table 3: Quality of conversations about serious illness in the intervention and control groups, stratified by the type of clinician who led the conversation

\begin{tabular}{|lccc|}
\hline \multicolumn{3}{|c|}{$\begin{array}{c}\text { Group; total score, }{ }^{*} \text { median } \\
\text { (IQR) }\end{array}$} & \\
\cline { 2 - 3 } & $\begin{array}{c}\text { Intervention } \\
n=55\end{array}$ & $\begin{array}{c}\text { Control } \\
n=28\end{array}$ & $p$ value \\
\hline Type of clinician & $9.0(7.0-12.0)$ & $4.0(3.8-6.0)$ & $<0.001$ \\
\hline $\begin{array}{l}\text { Attending physician } \\
\text { Resident or nurse } \\
\text { practitioner }\end{array}$ & $8.0(7.0-9.0)$ & $4.5(2.8-5.3)$ & 0.008 \\
\hline $\begin{array}{l}\text { Note: IQR = interquartile range. } \\
{ }^{*} \text { Maximum 17. }\end{array}$ & & \\
\hline
\end{tabular}

A recent multicentre study showed that patients on internal medicine wards are at risk for inappropriate end-of-life care, which is related to poor communication and poor documentation of conversations about serious illness. ${ }^{13}$ The improved accessibility and clarity of documentation we observed as a result of SICP implementation may increase the likelihood that these conversations will affect future care and reduce medical error related to interventions discordant with patient preferences.

In the present study, there was no significant difference between the intervention and control groups in the end-oflife care planning domain, and the difference in the lifesustaining treatments domain was not as pronounced as that in the domains of understanding of prognosis and illness, and values and goals. These findings are consistent with what Paladino and colleagues ${ }^{14}$ found with SICP implementation in the oncology setting. We hypothesize that conversations about serious illness are more values-oriented when clinicians follow the Serious Illness Conversation Guide. An important focus of the clinician training component of the SICP is to reorient clinicians to elicit values and goals during conversations regarding serious illness and to communicate prognostication with patients and their families, rather than lead procedure-focused conversations, which are typical of current practice.

Our study adds to the existing body of work that has studied the use of interventions to aid clinicians in having better conversations about serious illness. In particular, it expands on the use of the SICP in other clinical settings. For example, a similar analysis conducted after implementation of the SICP in the primary care setting showed an increased number of conversations regarding serious illness, and improved comprehensiveness of and accessibility to these conversations. ${ }^{10}$ Our findings are consistent with that study and suggest that the SICP is a flexible model that can be adapted successfully to inpatient and outpatient settings as well as to oncology and nononcology populations.

Although we found that SICP implementation was associated with statistically significantly higher scores for conversation quality compared to usual care, to our knowledge, there are no data correlating absolute differences in scores to other outcomes. This represents an opportunity for future research in this field. In addition, our study did not address the sustainability or cost-effectiveness of SICP implementation. Future work should focus on identifying sustainable, cost-effective strategies to implement the SICP or similar best practices in communication about serious illness into clinical practice and to increase their uptake by clinicians.

This paper reports the results of focused assessment of the quality of conversations about serious illness before and after SICP implementation at a single centre. We plan to report data from all 3 participating sites on process measures, patient-reported measures and clinician-reported measures, and on lessons learned during implementation.

\section{Limitations}

Owing to the nature of the intervention, researchers could not be blinded during data extraction, and coding of clinical notes summarizing conversations about serious illness required subjective interpretation. However, we used several strategies to mitigate against this risk of bias, such as having a second assessor code every 10th chart in duplicate and comparing assessors' results at regular intervals. In addition, our study did not use a randomized design, and because of differences in the sampling frames (including differences in seasonality), we cannot exclude the possibility that the intervention and control groups may have had some dissimilarities. However, we used the same eligibility criteria for the 2 groups and did not note any appreciable differences in demographic characteristics, comorbidities, use of health care services or laboratory values between the groups. The use of historical controls may have also overestimated the treatment benefit.

We did not deliver the intervention to all eligible patients identified. To the extent that missed patients were systematically different in ways that would have affected the quality of conversations about serious illness, this introduces a risk of bias into our findings.

We used the quality of documentation of conversations regarding serious illness as a surrogate for the quality of the conversations. As such, our study design is limited by the completeness and quality of documentation during the control and intervention periods. We also used the conversation with the highest codebook score, as opposed to taking the sum of scores from multiple conversations, in our analysis. However, in our experience performing the chart abstraction, different components of conversations about serious illness were not commonly documented over multiple different encounters. In addition, we excluded charts without a documented conversation in order to conduct a fair comparison of quality; therefore, our findings are a comparison of the quality of conversations before and after SICP implementation, conditional on a conversation's having occurred, and are not an assessment of the frequency of conversations during the intervention and control periods.

Finally, our study findings are based on the implementation of the SICP at a single academic teaching hospital. As a result, our results may not be transferable to other health care settings or other jurisdictions. 


\section{Conclusion}

In this single-centre retrospective chart review study, we found that the SICP, when implemented in a hospital setting, was associated with a higher quality of documented conversations regarding serious illness compared to usual care. Our findings suggest that a structured approach to triggering, conducting and documenting such conversations can enhance both the quality of the conversation and the retrievability of the documentation.

\section{References}

1. Davison SN. End-of-life care preferences and needs: perceptions of patients with chronic kidney disease. Clin 7 Am Soc Nephrol 2010;5:195-204.

2. Heyland DK, Allan DE, Rocker G, et al.; Canadian Researchers at the End-ofLife Network (CARENET). Discussing prognosis with patients and their families near the end of life: impact on satisfaction with end-of-life care. Open Med 2009;3:e101-10.

3. You JJ, Dodek P, Lamontagne F, et al.; ACCEPT Study Team and the Canadian Researchers at the End of Life Network (CARENET). What really matters in end-of-life discussions? Perspectives of patients in hospital with serious illness and their families. CMA7 2014;186:E679-87.

4. Heyland DK, Barwich D, Pichora D, et al.; ACCEPT (Advance Care Planning Evaluation in Elderly Patients) Study Team; Canadian Researchers at the End of Life Network (CARENET). Failure to engage hospitalized elderly patients and their families in advance care planning. 7AMA Intern Med 2013;173:778-87.

5. Yung VY, Walling AM, Min L, et al. Documentation of advance care planning for community-dwelling elders. 7 Palliat Med 2010;13:861-7.

6. Wendler D, Rid A. Systematic review: the effect on surrogates of making treatment decisions for others. Ann Intern Med 2011;154:336-46.

7. Bernacki R, Hutchings M, Vick J, et al. Development of the Serious Illness Care Program: a randomised controlled trial of a palliative care communication intervention. BM7 Open 2015;5:e009032.

8. Bernacki RE, Block SD.; American College of Physicians High Value Care Task Force. Communication about serious illness care goals: a review and synthesis of best practices. FAMA Intern Med 2014;174:1994-2003.

9. Bernacki R, Paladino J, Neville BA, et al. Effect of the Serious Illness Care Program in outpatient oncology: a cluster randomized clinical trial. $7 A M A$ Intern Med 2019;179:751-9.

10. Lakin JR, Koritsanszky LA, Cunningham R, et al. A systematic intervention to improve serious illness communication in primary care. Health Aff (Millwood) 2017;36:1258-64.

11. Charlson ME, Pompei P, Ales KL, et al. A new method of classifying prognostic comorbidity in longitudinal studies: development and validation. $\mathcal{F}$ Chronic Dis 1987:40:373-83.

12. Hirdes JP, Curtin-Telegdi N, Poss JW, et al. interRAI Contact Assessment (CA) form and user's manual: a screening level assessment for emergency department and intake from community/hospital. Rockport (MA): Open Book Systems; 2010.
13. Heyland DK, Ilan R, Jiang X, et al. The prevalence of medical error related to end-of-life communication in Canadian hospitals: results of a multicentre observational study. BM7 Qual Saf 2016;25:671-9.

14. Paladino J, Bernacki R, Neville BA, et al. Evaluating an intervention to improve communication between oncology clinicians and patients with lifelimiting cancer: a cluster randomized clinical trial of the Serious Illness Care Program. FAMA Oncol 2019;5:801-9.

Affiliations: Michael G. DeGroote School of Medicine (Ma, Riehm), Faculty of Health Sciences, McMaster University, Hamilton, Ont.; Harvard Medical School (Bernacki, Paladino); Department of Psychosocial Oncology and Palliative Care (Bernacki), Dana-Farber Cancer Institute; Ariadne Labs (Bernacki, Paladino), Brigham and Women's Hospital and Harvard T.H. Chan School of Public Health; Department of Medicine (Bernacki, Paladino), Brigham and Women's Hospital, Boston, Mass.; Division of General Internal and Hospitalist Medicine (You), Trillium Health Partners, Mississauga, Ont.; Departments of Medicine and of Health Research Methods, Evidence, and Impact (You), McMaster University, Hamilton, Ont.

Contributors: John You supervised the work. Christina Ma and Lauren Riehm contributed equally to the work. Christina Ma, Lauren Riehm and John You analyzed and interpreted the data and drafted the manuscript. All of the authors conceived and designed the study, revised the manuscript critically for important intellectual content, approved the final version to be published and agreed to be accountable for all aspects of the work.

Funding: This work was supported by research grant TG2013-03 from the Canadian Frailty Network, a Hamilton Health Sciences Research Administration, McMaster University Department of Medicine Medical Student Research Award, and Michael G. deGroote School of Medicine McMaster Medical Student Research Excellence Scholarships. Rachelle Bernacki and Joanna Paladino are supported by the Sojourns Scholar Leadership Program.

Data sharing: Deidentified raw data will be made available on request to the corresponding author, John You, John.You@thp.ca.

Acknowledgements: The authors thank Marilyn Swinton for her assistance with project coordination and Shelley Weniger for her activities as unit champion for the implementation of the Serious Illness Care Program at Hamilton General Hospital.

Disclaimer: None of the funders had a role in the conduct of the study, the decision to submit the work for publication or the writing of the manuscript.

Supplemental information: For reviewer comments and the original submission of this manuscript, please see www.cmajopen.ca/content/8/2/ E448/suppl/DC1. 